\title{
Study on Medical Prices Public Network and the Status Improvement of Medicine Prices
}

\author{
Yongqiang $\mathrm{Li}^{1, \text { a }}$ \\ ${ }^{1}$ Jiangxi University of Traditional Chinese Medicine, Nanchang, Jiangxi, 330004 \\ ${ }^{a}$ email
}

Keywords: Medical Prices, Network Publicity, Improvement Measures

\begin{abstract}
Since the reform and opening up, Chinese economic development momentum is much important and is near the top level in the world in many aspects, but the development speed is too fast, also brought a series of problems, especially in the medical field, medical virtual price Higher question has always been an important obstacle hinder the development of Chinese medical industry, but also largely reduces our people's happiness index. In this paper, medicines and medical equipment overpriced phenomenon are briefly discussed and the price of medical network publicity is discussed, hoping to lay a certain effect on improving the current situation of artificially high prices of medicine.
\end{abstract}

\section{Introduction}

With the continuous growth of our current economy, people's daily lives have also been significantly improved. But in the process of Chinese economic development, there are still many problems to be solved urgently needed, especially in health care. Moment of artificially high prices of medicines and medical equipment is widespread. According to the census of Health data show that the prevalence of residents is gradually improved, but the treatment rate declined significantly. Difficult and expensive medicines and drug prices artificially high and so on, resulting in the modern health care costs growing, while Chinese per capita income is difficult to keep up its growth rate, which also led to some extent the burden of medical expenses of our people is growing and even triggered a series of crisis of confidence, more and more people to modern medical institutions responded with skepticism.

\section{Status of Artificially High Prices of Medicines and Medical Facility Analysis}

First, there is a big manufacturer of medical products cost estimation difficult. Since pharmaceutical products need to be developed for a long time, but also requires a higher normative technical requirements, complex raw materials and varieties, and in the technical strength and talent reserves and other sectors, the major manufacturers have some differences, so also for different drugs approved scientific and reasonable product prices caused by a certain degree of influence. The reproduction link, the moment of the choice of drug pricing, still or cost-plus pricing method, and this method has already been eliminated in the international arena. Under the influence of this pricing method in the future to maximize profits, it is the process of manufacturing enterprises in the prices declared, often will be the actual cost of production of false, which means it will cause a phenomenon artificially high drug prices occurrence [1]. Secondly, since the majority of the company size is not large, there is a more serious repetitive construction phenomenon. According to relevant survey, the current Chinese pharmaceutical production enterprises, large enterprises the proportion was only $12 \%$, the rest of them are small and medium enterprises, and these enterprises due to poor production conditions, low management level reasons that in order to occupy in the fierce market competition in a favorable position, often to raise prices will be way more profitable, which also resulted in the occurrence of medical drugs artificially high.

First, since drug sales during the existence of the characteristics of their formation phenomenon artificially high prices brought a certain convenience. Drugs itself is a special character of commodities, particularly since some basic medicines, all have a certain degree of public interest 
and the amount of welfare, which also resulted in drug sales tend to occur very significant monopoly. The market also will largely monopoly has brought convenience to get the price profiteering. Secondly, medicines often there is more circulation, have some degree of increase on each link, and ultimately also resulted in artificially high prices seriously. Drugs developed from the following manufacturers generally need to rely on hospitals, retailers and many other aspects, they finally able to reach the hands of consumers [2]. And this whole process of circulation, on the one hand, storage and transportation costs will inevitably increase as the circulation of drugs and continue to improve; on the other hand increase the number of transfers of ownership of the goods, must also let the velocity decreases, resulting in each level increase phenomenon occurs. In some Western countries, the pharmaceutical market is more mature, the pharmaceutical distribution only after two or three links, but in our country it takes sixty-seven even more links, many links naturally will to some extent reduce its efficiency and effectiveness. Eventually we will get some auto rebates marketing approach to the efficiency and effectiveness of the losses from consumers back, and then it formed a phenomenon artificially high price.

\section{Countermeasures of Improving Medicine Prices Artificially High Effective}

First, from the source to begin treatment, pharmaceutical companies can make profits and medicines procurement and use of other links from each other. Want to drugs and medical equipment to be effective price regulation, must begin to govern its source, the production companies strict supervision, to facilitate their profits and be able to contact between drug procurement and use of open, especially to pair unfair competition behavior of enterprises prevention [3]. Relevant government agencies in the regulatory process, to focus on quality control to ensure that each batch of products are able to Chinese relevant pharmaceutical manufacturing standards are consistent, and for other production companies, cost and profit problems, you can through the market for reasonable regulation of the rational allocation of resources, of the production and sales to make reasonable adjustments. Second, medical institutions internal distribution system is discussed for continuous innovation and improvement. On the current distribution system of internal medical institutions to improve and perfect the relevant government agencies as the role of referee in their improvement process should be worked out reasonable rules, to be effective nonprofit medical institutions clear and Government investment were increasing, prompting the idea of creating a highly profitable state-owned hospitals could be reduced, more investment to improve service attitude, medical treatment, medical expenses and working capital resources for patients to bring more quality services. State investment be increased from a certain extent, that is to redesign pay health workers will contact the hospital and medicine between the peel off, prompting health workers to rely on drugs to get high-paying sales phenomenon can be reduced, safeguard its stable income, enabling it to bring more high-quality patient care and treatment standards.

For now, many of our top three hospitals are beginning to integrate into daily medical practice in computer networks, on the appointment registration, payment and a series of links are beginning to use the computer network technology, but the ability to achieve the reform goals, need to be further strengthened the study. First, the Ministry of Health should enact a uniform price standard, and on the Internet talking about the price of each drug, inspection fees and other social public, not only in their own intranet also should expand publicity channels, prompting numerous masses can visit before, to be effective contrast, scientific and reasonable medical treatment to their condition to select channels. In recent years, a lot of people to hold down prices for the issue continue to explore effective solutions, arising from such kind of "down drug prices Network" from the site can see a lot of drug prices, mostly in the ten yuan hereinafter, but from the retail price, the difference is huge, there are dozens there are hundreds. For example: a user query the Liaoning produced a Kechuanning its prices less than four yuan, but was sold in the retail forty-six yuan. "Down drug prices Network" is implemented in a transparent line drug prices, to show the people to hold down prices of the problem. To some extent, although the "lower drug prices Network" is a kind of personal behavior, we will not consider its purpose, but its relative showcase contemporary Chinese 
medical problems are worthy to hold down prices of all learning, but also received a unanimously recognized by many patients [4]. Thus, the transparency of the hospital's medical expenses increase can be largely a beneficial impact on drug prices drop and health care cost savings.

Relevant national WHO experts to present all kinds of hospital medical standards, social reputation, will organize different medical services out of specification, especially in the prescription segment, will develop a new service specification out, their doctors, when out of the treatment prescription, should be combined with the patient's condition put forward two to three kinds of options, and indicates the specific cost of each prescription, to guide patients with their own economic situation and the condition of the time, autonomous, rational choice of drugs .

\section{Conclusion}

In short, medical and health services are important in people's daily lives, is a important guarantee to ensure that the masses can afford many important disease protection, weather the masses can afford medical price is what our government's responsibility lies. Therefore, the key to health care reform is that whether government decision-makers pay attention to people's livelihood. Only government policy make continuous capital investment to explore and strengthen the universal free health care reform, continue to strengthen health care costs publicized prices, can solve medical care and a series of medical issues and to promote harmonious and healthy development of our society.

\section{References}

[1] Cai Yu, Gong Gang, Zhang Qiancheng. Doctors to get rid of regression value of "drug dependent doctors" - based on the theory of argumentation model Perspective [J]. Nankai Economic Research, 2013, 01: 40-52.

[2] Dong Xiaolin, Cai Xin. Situation medicine price management analysis and policy recommendations - on Guangdong Sunshine drugs online auction purchase price [J]. Chinese prices, 2012, 07: 35-39.

[3] Li Wei. drug price Market Reform- On Jiangxi pharmaceutical price reform and policy improvement [J]. Monthly price, 2014,08: 5-11...

[4] Liu Quanhong, Liu Fang. Industrial Policy and Development Status of Chinese Pharmaceutical Industry: Problems and Policy Recommendations [J]. Economic Research, 2014, 32: 39-67. 